\title{
KELOMPOK DUKUNGAN UNTUK CAREGIVER ORANG DENGAN SKIZOFRENIA
}

\author{
Adhityawarman Menaldi, Hellen Citra Dewi
}

Fakultas Psikologi Universitas Indonesia

Jl. Lkr. Kampus Raya Blok Mawar No.5, RT.3/RW.8, Pondok Cina, Beji, Kota Depok, Jawa Barat 16424

a.menaldi@ui.ac.id

\begin{abstract}
Caregiver's burden not only affects the mental health of the caregiver, but also to the treated patient. This study aims to examine the effectivity of support group intervention to reduce caregiver burden among mothers of individuals with schizophrenia. The study used a quasi-experimental one-group, before-after (pretest-posttest) design, involving nine participants. The intervention consisted of four sessions, including pre and postintervention session with three hours duration per session at average. Caregiver's burden was measured using the Zarit Burden Interview (ZBI). Qualitative data on the participants' experiences during intervention were collected using unstandardized nonstructured interview. Quantitative data were analyzed using Wilcoxon Signed Ranks Test while qualitative data were analyzed using content analysis. The result shows that the interventions proved significantly reduced caregiver's burden scores $(Z=-2.67 ; p=0.008)$. In addition, the participants reported more positive thoughts, better control on negative emotions, positive meaning, and new hope about their future after the intervention. Participants also reported to gain new knowledge, coping strategies skills as caregiver and how to take care of their children with schizophrenia.
\end{abstract}

Keywords: support group; caregiver; caregiver burden; schizophrenia

\begin{abstract}
Abstrak
Beban caregiver tidak hanya memengaruhi kesehatan mental caregiver, melainkan juga pasien yang sedang dirawat. Penelitian ini bertujuan untuk menguji efektivitas intervensi dalam bentuk kelompok dukungan dalam menurunkan beban caregiver pada ibu yang memiliki anak dengan skizofrenia. Penelitian ini menggunakan desain kuasi eksperimen berupa one group, before after (pretest-posttest) design, terhadap sembilan orang partisipan. Intervensi terdiri dari empat sesi, termasuk di dalamnya sesi pre dan pasca intervensi dengan durasi rata-rata tiga jam per sesi. Beban caregiver diukur menggunakan Zarit Burden Interview (ZBI). Data kualitatif mengenai pengalaman partisipan selama mengikuti intervensi juga dikumpulkan melalui unstandardized nonstructured interview. Data kuantitatif dianalisis menggunakan Wilcoxon Signed Ranks Test sedangkan data kualitatif dianalisis melalui analisis konten. Hasil penelitian menunjukkan bahwa intervensi kelompok dukungan terbukti secara signifikan menurunkan beban caregiver $(Z=-2,670 ; p=0,008)$. Selain itu, partisipan melaporkan adanya pikiran yang lebih positif, pengendalian emosi negatif yang lebih baik, makna positif serta harapan baru tentang masa depan mereka pasca mengikuti keseluruhan sesi intervensi. Partisipan juga melaporkan memperoleh pengetahuan baru, keterampilan strategi coping sebagai caregiver, dan cara merawat anak dengan skizofrenia.
\end{abstract}

Kata kunci: kelompok dukungan; caregiver; beban caregiver; skizofrenia

\section{PENDAHULUAN}

Skizofrenia merupakan gangguan psikotik yang ditandai dengan gangguan utama dalam pikiran, emosi, dan perilaku serta terganggunya keberfungsian dalam hidup (Kring, Johnson, Davidson, \& Neale, 2012). Dengan kondisi tersebut, orang dengan skizofrenia tidak mampu mengurus kebutuhannya sendiri, terlebih kebutuhan keluarga. Keberfungsian peran dari komunitas menjadi salah satu aspek yang penting untuk ditingkatkan, khususnya keluarga, dalam merawat anggota keluarga yang memiliki gangguan skizofrenia (Jungbauer, Wittmund, Dietrich, \& 
Angermeyer, 2004). Tujuan dari pemfungsian keluarga adalah agar orang dengan skizofrenia tetap mampu menjalani fungsi kehidupannya sehari-hari. Akan tetapi faktanya tidak semua orang dengan skizofrenia mendapatkan perawatan yang layak dari keluarganya. Satu survei di Indonesia bahkan menemukan terdapat $14,3 \%$ atau sekitar 57.000 orang dengan skizofrenia di Indonesia yang dipasung oleh keluarganya sendiri di rumah (Armandani, 2014).

Kenyataannya, hidup dengan pasien skizofrenia memang tidaklah mudah (Chien, 2008; Jungbauer dkk., 2004). Karakteristik dari gangguan ini menyebabkan beragam pola keseharian dalam keluarga menjadi tidak teratur, namun demikian peran sebagai caregiver tidak dapat diabaikan begitu saja oleh keluarga. Hal ini dikarenakan anggota keluarga sebagai caregiver informal memiliki peran dan tanggung jawab yang lebih besar dalam proses perawatan. Menurut Duxbury, Higgins, dan Schroeder (2009) caregiver informal atau yang sering disebut family caregiver adalah caregiver yang menyediakan bantuan kepada pasien yang memiliki hubungan pribadi dengan caregiver, seperti hubungan keluarga, teman atau tetangga yang tidak dibayar untuk melakukan tugas merawat tersebut.

Dalam sebuah keluarga, walaupun semua anggota keluarga berperan dalam proses perawatan, namun umumnya ibulah yang memiliki peran lebih banyak sebagai caregiver informal utama. Hal ini disebabkan oleh adanya peran tradisional dan identitas diri yang dimiliki ibu untuk merawat anggota keluarganya. Selain itu, pada diri caregiver yang merupakan seorang ibu, juga terdapat perasaan bersalah selama proses perawatan anak mereka. Misalnya perasaan bersalah karena merasa tidak merawat keluarganya dengan baik (Gupta, Solanki, Koolwal, \& Gehlot, 2014) Hal ini yang membuat ibu terus berjuang dalam proses perawatan untuk anggota keluarga mereka. Wiener (2011) juga menambahkan bahwa ibu sebagai caregiver dianggap memiliki waktu yang lebih banyak untuk terlibat dalam perawatan anak. Dengan peran yang dijalankan oleh ibu tersebut, tidak heran jika ibu sebagai caregiver informal utama dinyatakan memiliki beban yang lebih tinggi daripada anggota keluarga lain.

Secara umum, beberapa penelitian mengungkap bahwa adanya beban subjektif pada caregiver disebabkan oleh beragam hal. Stigma, merupakan salah satu faktor yang cukup besar. Stigma, atau adanya anggapan atau label yang keliru mengenai suatu fenomena sosial tertentu, dinilai menjadi faktor yang berat karena sifat stigma yang melekat pada individu, dan pada kasus ini juga pada keluarga (Angermeyer, Schulze, \& Dietrich, 2003). Stigma bisa berasal dari luar individu, maupun dari diri sendiri. Pada kasus orang dengan skizofrenia, salah satu stigma terbesar bahkan muncul dari keluarga sendiri, yang erat kaitannya dengan ketidakpahaman anggota keluarga mengenai dinamika orang dengan skizofrenia (Larson \& Corrigan, 2008). Hal-hal lainnya seperti perubahan keberfungsian anggota keluarga yang skizofrenia, jumlah anggota keluarga serumah, serta tambahan pengeluaran finansial yang terjadi, juga menjadi faktor yang menentukan besaran beban bagi caregiver (Panayiotopoulous, Pavlakis, \& Apostolou, 2013).

Beban caregiver (caregiver burden) adalah respon multidimensional atas penilaian negatif, stres, dan ketegangan yang dipersepsikan sebagai hasil dari merawat individu yang sakit (Kim, Chang, Rose \& Kim, 2011; Gupta \& Sharma, 2013). Tingginya beban pada ibu sebagai caregiver diperkuat oleh studi yang melaporkan bahwa terdapat beban caregiver informal yang lebih tinggi dalam kasus skizofrenia (Kumar \& Gupta, 2014). Seperti temuan pada penelitian Panayiotopoulous, Pavlakis, \& Apostolou (2013), yang menyebutkan tekanan, rasa cemas, bantuan (supervision), penguatan (encouragement), serta dampak finansial merupakan sumber-sumber beban bagi para 
caregiver. Belum lagi bila kita menilik karakteristik gangguannya, baik simtom positif ataupun negatif yang menjadi ciri dari pasien psikotik/skizofrenia, secara bersamasama juga dapat menimbulkan beban bagi caregiver (Pratima \& Jena, 2011). Hal yang juga mengindikasikan adanya beban pada caregiver skizofrenia adalah stigma negatif dari masyarakat atas kehadiran simtomsimtom tersebut (Pratima \& Jena, 2011; Schene, Wijngaarden \& Koeter, 1998). Tampilan orang dengan skizofrenia yang sering berbicara tidak koheren, delusi dan halusinasi, membuat stigma menjadi mudah muncul. Di Indonesia, ada sebutan "orang gila" untuk individu yang memunculkan gejala-gejala psikotik, namun di belahan dunia lain pun ternyata stigma tersebut juga masih mudah ditemukan.

Stigma negatif yang begitu kuat sering membuat keluarga merasa terisolasi dalam lingkungan masyarakat. Anggota keluarga juga sebetulnya mengalami perasaan kehilangan dan kesedihan atas kondisi tersebut (Miller dkk., dalam Schene, Wijngaarden \& Koeter, 1998). Mereka berhadapan dengan emosi malu, perasaan bersalah, takut, dan marah atas kondisi yang mereka alami. Selain itu, kondisi usia ibu sebagai caregiver yang semakin tua juga mengembangkan perasaan khawatir terhadap masa depan anggota keluarga yang dirawatnya (Gupta dkk., 2014).

Persepsi caregiver terhadap beban yang diemban tersebut berdampak langsung pada kehidupannya (Chien, 2008). Beban caregiver ini kemudian menjadi penyebab gangguan kondisi fisik, psikologis, emosional, dan fungsi kesehatan dari caregiver (Zarit dkk. dalam Kim dkk., 2011; WHO dalam Bharti, 2015). Selain itu, merawat pasien skizofrenia juga dapat mengganggu tatanan kehidupan sosial (Brody dalam Chou, Liu, \& Chu, 2002; Jungbauer dkk., 2004). Walaupun banyaknya beban yang harus dihadapi oleh keluarga, Schene dkk. (1998) mengembangkan fakta bahwa anggota keluarga harus mengatasi tugas dan permasalahan tersebut apapun tantangannya. Sejalan dengan paparan tersebut, salah satu penelitian mengenai caregiver pasien memperlihatkan bahwa rata-rata kualitas hidup para caregiver orang dengan skizofrenia lebih rendah ketimbang caregiver pasien dengan penyakit lain (Guan, Xiang, Ma, Weng, \& Liang, 2016). Kondisi inilah yang menjadi perhatian dalam proses perawatan, sehingga jelas bahwa caregiver sangat membutuhkan bantuan.

Menurut Navidian, Kermansaravi, dan Rigi (2012) caregiver dari pasien dengan gangguan mental, seperti skizofrenia memang membutuhkan bantuan dalam proses perawatan karena kurangnya informasi dan dukungan. Banyak metode intervensi yang dapat diberikan untuk mengurangi beban caregiver, akan tetapi, di antara semua metode, support group (kelompok dukungan) dinilai lebih efektif menjangkau kebutuhan psikologis dan sosial dari para caregiver (Chou dkk., 2002). Kelompok dukungan merupakan jenis terapi psikologis yang dilakukan dalam kelompok, dengan kegiatan utama yaitu para anggotanya saling memberikan dukungan emosional dan informasi kepada orang lain dengan permasalahan yang sama (Kurtz, 1997). Kelompok dukungan dinilai lebih efektif karena tidak hanya menyasar pada perubahan kognitif seperti intervensi individual pada umumnya, tetapi juga dikombinasikan dengan dukungan sosial secara langsung dari sekelompok orang (Cooke dkk. dalam Toseland, Haigler, \& Monahan, 2011). Kelompok dukungan juga ditemukan tidak hanya membantu secara emosional, namun hasil yang lebih terukur seperti kepatuhan menjalankan pengobatan juga dapat meningkat pada pasien yang mengikuti kelompok dukungan, seperti temuan pada riset oleh Chime, Arinze-Onyia, \& Obiuonu (2018) pada pasien HIV/AIDS di Nigeria. Selain itu, kelompok dukungan dapat menjadi sebuah wadah untuk mengatasi perasaan sendiri dalam tanggung jawab mereka sebagai caregiver dan mengatasi kehidupan sosial yang terbatas 
(Chou dkk., 2002). Pada akhirnya, jika beban caregiver berkurang, tentu akan banyak dampak positif yang dapat dirasakan oleh caregiver dan care receiver (Adelman, dkk., 2014).

Berkaitan dengan penanganan komprehensif bagi caregiver dan juga care receiver tersebut, beberapa penelitian menyebutkan bahwa salah satu faktor yang penting namun sering belum menjadi perhatian adalah sistem perawatan atau sistem kesehatan yang baik di suatu negara. Temuan Guan dkk. (2016) menyebutkan bahwa ada perbedaan kualitas hidup caregiver yang cukup tajam saat mereka membandingkan kualitas hidup kelompok caregiver di Hongkong, yang sudah memiliki sistem perawatan pasien gangguan mental yang baik, dengan kelompok di Beijing, China, yang sistemnya masih terfragmentasi. Terfragmentasi di sini memiliki maksud bahwa penanganan dilakukan bergantung pada gerakan masyarakat yang merasa penting, dan belum ditata secara baik oleh pemerintahan. Hal senada juga ditemukan pada penelitian terdahulu di Nigeria (Ohaeri, 2001), di mana Nigeria pada saat itu sama sekali belum memiliki tatalaksana penanganan pasien gangguan mental, sehingga penanganan sangat bergantung pada keluarga maupun komunitas-komunitas di masyarakat. Kasus senada juga ditemukan di Cyprus, di mana angka kualitas hidup caregiver pasien skizofrenia terbilang rendah (Panayiotopoulous dkk., 2013). Meskipun demikian, ada benang merah dari penelitian-penelitian tersebut, bahwa penanganan orang dengan skizofrenia tidak harus menunggu sistem yang baik atau menjalani perawatan di rumah sakit. Perawatan berbentuk dukungan dan jejaring yang berbasis komunitas (seperti kelompok dukungan), ditemukan juga memiliki dampak positif baik bagi caregiver maupun care receiver.

Pertanyaan selanjutnya yang perlu dijawab adalah "Apakah kelompok dukungan efektif mengurangi beban pada ibu yang berperan sebagai caregiver untuk orang dengan skizofrenia di RS X?". Dengan demikian, tujuan dari penelitian ini adalah untuk melihat sejauh mana intervensi berupa kelompok dukungan efektif dalam mengatasi beban caregiver yang tinggi pada ibu yang harus merawat anak dengan skizofrenia. Melalui intervensi kelompok ini diharapkan dapat terjadi peningkatan kualitas hidup pada caregiver dan orang dengan skizofrenia.

\section{METODE}

Penelitian ini menggunakan metode campuran berupa kuantitatif dan kualitatif. Hal ini dilakukan mempertimbangkan dalam intervensi psikologis, ada unsur pengalaman subjektif yang dapat diolah lebih mendalam dengan metode analisis konten. Secara kuantitatif, desain yang digunakan merupakan desain penelitian kuasi eksperimen yang termasuk dalam one group before-after pretest-posttest design (Kerlinger \& Lee, 2000). Desain ini dilakukan pada satu kelompok dengan melihat perubahan sebelum dan setelah pemberian intervensi kelompok dukungan, yang didahului dengan pemberian pretest dan diikuti dengan pemberian posttest di akhir penelitian. Perubahan skor diukur dengan membandingkan perbedaaan skor beban caregiver di awal penelitian dan di akhir penelitian, menggunakan analisis Wilcoxon Signed Ranks Test, sesuai dengan tujuan untuk melihat kebermaknaan perubahan pasca adanya treatment yang dilakukan pada sampel yang kecil (Gravetter \& Forzano, 2016). Analisis lebih lanjut dilakukan dengan membuat simpulan dari wawancara yang dilakukan setelah intervensi dilakukan untuk masingmasing individu. Wawancara dilakukan agar data yang tergali lebih memiliki makna, mempertimbangkan adanya kemungkinan ketidakakuratan data dari partisipan karena tingkat pendidikan partisipan dalam kategori yang mungkin jarang terpapar dengan kuesioner lapor diri seperti yang digunakan dalam penelitian ini. 


\section{Partisipan Penelitian}

Partisipan yang terlibat dalam kelompok dukungan ini adalah sembilan orang ibu kandung dari orang dengan skizofrenia yang menjalani rawat jalan di bagian Psikiatri Rumah Sakit X. Secara umum, mereka memiliki status sosial ekonomi menengah ke bawah. Para partisipan ini juga merupakan pasien kelas dua atau tiga selama perawatan di RS X. Penelitian ini tidak membatasi usia anak yang dengan gangguan skizofrenia maupun usia caregiver yang akan menjadi partisipan dalam penelitian ini. Secara spesifik, karakteristik partisipan dalam penelitian ini yaitu: a) Partisipan adalah seorang wanita yang berperan sebagai ibu dan telah menjadi caregiver informal untuk anak kandungnya yang memiliki gangguan skizofrenia; b) Partisipan tinggal satu rumah dengan anak yang memiliki gangguan skizofrenia; c) Partisipan telah menjadi caregiver selama minimal satu tahun; d) Partisipan melakukan perawatan selama minimal 20 jam dalam seminggu; e)
Partisipan memiliki beban caregiver yang berada pada rentang beban sedang sampai berat dan beban berat (skor ZBI 41-60 dan 61-88); f) Partisipan bersedia mengikuti penelitian intervensional dalam format kelompok dukungan.

Sebelum intervensi diberikan, peneliti melakukan pengukuran awal kepada sembilan partisipan untuk mengetahui gambaran bebannya. Secara kuantitatif, mereka memiliki beban berat (skor ZBI 6188) dan sedang hingga berat (skor ZBI 4160). Secara kualitatif maknanya adalah mereka merasa terbebani oleh peran mereka sebagai caregiver baik secara objektif maupun subjektif, kurang mendapatkan dukungan sosial baik dari keluarga maupun lingkungan masyarakat, serta minim pengetahuan mengenai skizofrenia dan cara mengatasi beban caregiver. Informasi demografi dari partisipan penelitian secara lengkap tersaji dalam Tabel 1 .

Tabel 1.

Gambaran Partisipan Intervensi

\begin{tabular}{ccllllcl}
\hline Inisial & Usia & \multicolumn{2}{c}{ Pendidikan } & Status & $\begin{array}{c}\text { Lama } \\
\text { Merawat }\end{array}$ & $\begin{array}{c}\text { Skor } \\
\text { pre-test } \\
\text { ZBI }\end{array}$ & Jumlah Sesi \\
\hline K & 47 & $\begin{array}{l}\text { SD } \\
\text { lulus) }\end{array}$ & (Tidak & Menikah & 4 tahun & 75 & 4 (Selesai) \\
A & 54 & SD & Menikah & 8 tahun & 70 & 4 (Selesai) \\
Y & 58 & SMA & Menikah & 2 tahun & 45 & 4 (Selesai) \\
T & 57 & SMP & Janda & 15 tahun & 75 & 3 (Absen \\
& & & Menikah & 13 tahun & 52 & 4 (Selesai) \\
S & 57 & - & Janda & 7 tahun & 65 & 4 (Selesai) \\
SM & 59 & SD & Janda & 12 tahun & 61 & 4 (Selesai) \\
E & 67 & SMP & Menikah & 7 tahun & 70 & 4 (Selesai) \\
YA & 45 & - & Janda & 16 tahun & 57 & 4 (Selesai) \\
AM & 69 & SD & & & & \\
\hline
\end{tabular}

\section{Pengukuran}

Dalam penelitian ini, pengukuran yang digunakan untuk mengukur beban caregiver adalah Zarit Burden Interview (ZBI) yang dikembangkan pertama kali oleh Zarit, Reever, dan Bach-Peterson pada tahun 1980. ZBI merupakan alat ukur dengan bentuk lapor diri yang terdiri dari 22 item, yang sangat umum digunakan untuk mengukur beban baik secara objektif maupun subjektif (Seng, Luo, Ng, Lim, Chionh, Goh, \& Yap, 2010). Peneliti sudah melakukan uji keterbacaan dan uji reliabilitas ulang dengan konsistensi internal Cronbach Alpha senilai 0,945, sehingga ZBI dapat langsung digunakan dalam penelitian ini. Kategorisasi 
skor pada ZBI ada empat, yaitu 0-21 (tidak terbebani atau beban rendah), 21-40 (beban ringan sampai sedang), 41-60 (beban sedang sampai berat) dan 61-88 tergolong terbeban berat (dalam Hebert, Bravo, \& Preville, 2000). ZBI diberikan sebelum dan setelah pelaksanaan intervensi. Secara kuantitatif, kelompok dukungan dianggap efektif jika di akhir intervensi tingkat beban caregiver menurun.

Untuk melengkapi data yang dibutuhkan, peneliti juga melakukan wawancara individual terhadap partisipan untuk melihat efek penerapan kelompok dukungan dalam mengurangi beban. Peneliti meminta partisipan untuk mendeskripsikan perubahan yang dirasakan setelah mengikuti intervensi selama empat sesi. Pertanyaan wawancara akan berfokus pada kondisi beban caregiver dan kepuasan partisipan dalam intervensi kelompok dukungan ini. Data yang didapat kemudian dibandingkan antara sebelum intervensi dan sesudah intervensi.

\section{Prosedur Intervensi}

Intervensi yang akan dilakukan adalah menggunakan teknik kelompok dukungan. Dalam intervensi ini, peneliti akan berperan sebagai fasilitator yang memfasilitasi proses kelompok dukungan sekaligus konselor pada saat sesi konseling individual. Intervensi kelompok dukungan dilaksanakan selama empat kali pertemuan setiap minggu di bulan Mei 2016. Pertemuan kelompok dukungan ini dirancang berlangsung selama \pm 3 jam setiap pertemuan, yaitu dimulai pukul 09.00 dan berakhir pada pukul 12.00. Pemilihan waktu tersebut mempertimbangkan kegiatan yang akan diberikan dalam setiap sesi dan faktor kondisi partisipan. Setiap sesi dalam kelompok dukungan berisi kegiatan yang sudah dirancang oleh peneliti. Kegiatan dalam kelompok dukungan ini menggunakan beberapa metode, antara lain ceramah, diskusi dalam kelompok, permainan, bermain peran, dan studi kasus. Kemudian peneliti akan menanyakan hasil refleksi dan juga tilikan yang partisipan dapatkan dari proses atau kegiatan yang telah dilakukan.
Peneliti juga memberikan tugas rumah setiap selesai sesi sebagai “jembatan" untuk pembahasan topik di sesi berikutnya.

Dalam penyusunan modul intervensi, peneliti melakukan dua tahapan yaitu melakukan asesmen kebutuhan partisipan, dan studi literatur berkaitan dengan modul kelompok dukungan yang sudah ada. Pertama, berdasarkan asesmen awal yang telah dilakukan, peneliti menemukan bahwa perubahan kondisi anak yang dengan gangguan skizofrenia membuat para keluarga merasa kehilangan harapan dan mengalami perubahan peran dan tanggung jawab yang lebih berat. Mereka juga harus menghadapi isolasi dari lingkungan masyarakat dan minimnya dukungan sosial karena adanya stigma negatif. Hal tersebut diperkuat oleh sudut pandang praktisi profesional, yaitu psikolog dan perawat RS X yang melihat dinamika keluarga pasien di RS X. Kondisi yang ada tersebut membuat para keluarga, khususnya caregiver membutuhkan bantuan psikologis. Hal ini terutama menyasar pada kebutuhan akan dukungan sosial dan mengatasi beban yang dirasakan.

Kedua, peneliti melakukan studi literatur dengan memelajari modul kelompok dukungan yang telah dikembangkan sebelumnya untuk caregiver skizofrenia. Peneliti kemudian menyusun modul yang mengacu pada modul kelompok dukungan oleh Chou dkk. (2002) dan Chien, Chan, dan Thompson (2006). Chou dkk. (2002) membuat modul intervensi yang mengacu dari Caregiver Support Group Procedure Manuals (CSGPM) yang dimodifikasi dan dikembangkan oleh Zarit dkk. pada tahun 1983. Secara umum, komponen dari modul dalam penelitian ini sama dengan yang diuraikan dalam penelitian Chou dkk. (2002) yaitu information, problem solving, coping dan support. Komponen tersebut kemudian diuraikan dari delapan sesi pada CSGPM menjadi empat sesi dengan satu prasesi dan satu pascasesi. Rangkuman modul yang telah dikembangkan oleh peneliti tersaji dalam Tabel 2. 
Tabel 2.

Sesi dan Kegiatan Kelompok Dukungan

\begin{tabular}{|c|c|}
\hline Sesi & Kegiatan \\
\hline $\begin{array}{l}\text { Pra Sesi } \\
\text { (Pretest) }\end{array}$ & Asesmen awal \\
\hline Sesi 1 & $\begin{array}{l}\text { a. } \\
\text { Perkenalan mengenai } \\
\text { kelompok dukungan } \\
\text { Identifikasi permasalahan dan } \\
\text { beban yang dialami caregiver } \\
\text { melalui diskusi tentang emosi } \\
\text { caregiver dan perasaan yang } \\
\text { berhubungan dengan } \\
\text { perawatan }\end{array}$ \\
\hline Sesi 2 & $\begin{array}{l}\text { a. Psikoedukasi mengenai } \\
\text { masalah perilaku umum yang } \\
\text { berkaitan dengan skizofrenia } \\
\text { b. Mengatasi reaksi terhadap } \\
\text { beban caregiver dengan } \\
\text { membangun penilaian positif } \\
\text { terhadap proses perawatan } \\
\text { Penambahan materi yang mengacu } \\
\text { pada sesi keenam dan ketujuh } \\
\text { CSGPM: } \\
\text { c. Mengenali sumber daya baik } \\
\text { dari diri sendiri maupun dari } \\
\text { lingkungan } \\
\text { d. Mempelajari teknik relaksasi }\end{array}$ \\
\hline Sesi 3 & $\begin{array}{l}\text { a. } \begin{array}{l}\text { Mengelola dan } \\
\text { mengekspresikan emosi } \\
\text { secara lebih efektif kepada } \\
\text { care receiver }\end{array} \\
\text { b. Mempelajari teknik coping } \\
\text { yang lebih efektif } \\
\text { c. Mempelajari komunikasi dan } \\
\text { ekspresi emosi kepada care } \\
\text { receiver }\end{array}$ \\
\hline Sesi 4 & 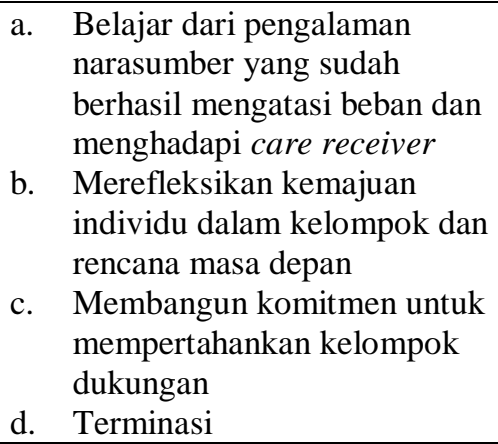 \\
\hline $\begin{array}{l}\text { Post sesi } \\
(\text { Posttest })\end{array}$ & $\begin{array}{l}\text { Asesmen akhir dengan partisipan } \\
\text { (wawancara post intervention dan } \\
\text { pengisian alat ukur ZBI) }\end{array}$ \\
\hline
\end{tabular}

\section{Analisis Data}

Data pre dan post pemberian intervensi kemudian dianalisis menggunakan Wilcoxon Signed Ranks Test dengan bantuan perangkat lunak SPSS. Analisis dilakukan untuk melihat sejauh mana adanya perbedaan terjadi sebagai efek dari pemberian intervensi. Selain itu, peneliti juga melakukan wawancara sebagai pendekatan analisa data kualitatif hasil pelaksanaan intervensi. Sesuai dengan Poerwandari (2013), wawancara yang dilakukan berupa unstandardized nonstructured interview. Wawancara ini bertujuan untuk menggali data mengenai latar belakang partisipan yang meliputi identitas diri dan keluarga, hubungan partisipan dengan keluarga, pola pengasuhan dan komunikasi dalam keluarga serta tempat tinggal. Data berikutnya yang digali melalui wawancara adalah riwayat keluhan yang meliputi pengalaman dan perasaan merawat anak dengan skizofrenia, cara mengetahui, awal menjadi caregiver, proses perawatan yang dilakukan, tugas, masalah yang muncul, hambatan yang muncul yang membuat partisipan merasa perlu mendapatkan bantuan, konsekuensi dari hambatan, serta upaya mengatasi hambatan yang pernah dilakukan. Setiap respons partisipan setiap sesi kemudian dibandingkan lalu disusun simpulan. Perbandingan antara aspek-aspek diri partisipan sebelum menjalani intervensi dan setelah menjalani intervensi kemudian ditelaah dan dirangkum dalam uraian kesimpulan per-partisipan sebagai acuan untuk melihat keberhasilan intervensi yang dilakukan.

\section{HASIL DAN PEMBAHASAN}

Intervensi dilaksanakan sebanyak empat kali pertemuan pada tanggal 23 April, 30 April, 7 Mei dan 14 Mei 2016 di beberapa tempat pertemuan di kota Bogor yang dapat disewa peneliti dengan dasar ketersediaan tempat. Sejumlah empat sesi inti dari intervensi dilaksanakan tanpa hambatan yang berarti. Setelah sesi inti dilaksanakan, skor ZBI partisipan kembali diukur untuk melihat perubahan kondisi partisipan. Seluruh partisipan terlihat mengalami perubahan kondisi terkait beban caregiver setelah menjalani sesi kelompok dukungan. Keberhasilan penurunan beban caregiver 
yang terjadi disebabkan oleh banyak dinamika dalam proses kelompok dukungan itu sendiri seperti yang akan diungkap dalam bagian mengenai data wawancara pascasesi. Grafik hasil pengukuran pra dan pascasesi kelompok dukungan tersaji dalam Gambar 1. Dari tabel tersebut dapat dilihat bahwa ada penurunan untuk masing-masing partisipan sebanyak rata-rata 43 poin. Secara umum, yaitu 8 dari 9 partisipan, dapat mengikuti kelompok dukungan secara aktif dan kooperatif. Setelah mengikuti kelompok dukungan, mereka merasakan perubahan beban yang lebih positif dan merasa puas atas keterlibatan mereka dalam kelompok dukungan. Manfaat serupa memang dirasakan oleh beragam temuan mengenai manfaat pelaksanaan kelompok dukungan yang telah dilakukan seperti pada penelitian Henriksson, Arestedt, Benzein, Ternestedt, dan Andershed (2012), juga pada riset oleh Magnani, Lenoci, Balduzzi, Artioli, dan Ferri (2017), mengenai perasaan dan pemaknaan caregiver dan juga kualitas hidup pasien. Mereka lebih mampu melihat makna dan harapan positif dari kondisi dan peran yang dijalankannya, mengatasi berbagai emosi negatif, lebih mampu berpikir positif dalam menghadapi masalah, membuat rencana untuk penyelesaian masalah dan mulai memperbaiki pola komunikasi yang lebih efektif dengan care receiver dan anggota keluarga lain. Selanjutnya, mereka juga membagi ilmu pengetahuan yang didapatkan dari kelompok dukungan kepada anggota keluarga lain di rumah. Mereka juga membangun kohesivitas kelompok untuk keberlangsungan kelompok dukungan ini. Rangkuman yang terjadi selama sesi dapat dilihat pada Tabel 3 .

Secara perhitungan statistika dari sembilan partisipan, didapatkan rata-rata skor ZBI sebelum menjalani intervensi adalah sebesar $62,89(S D=6,679)$. Mengacu pada pengkategorisasian skor, maka dapat dikatakan bahwa rata-rata beban partisipan penelitian ini menurut ZBI, adalah berada pada kategori berat. Sementara itu, setelah menjalani intervensi berupa kelompok dukungan, hasil pengukuran rata-rata skor beban partisipan turun menjadi 19,89 ( $S D=$ 11,062 ). Menurut kategori beban pada ZBI, skor ini termasuk dalam golongan tidak terbebani atau terbeban rendah. Artinya, setelah menjalani intervensi, ada perubahan yang cukup besar dirasakan oleh para partisipan, sebagai efek dari intervensi yang diberikan. Analisis lebih lanjut secara statistika dilakukan untuk melihat signifikansi perubahan yang terjadi menunjukkan adanya perubahan yang signifikan secara statistik $(Z=-2,670 ; p=0,008)$.

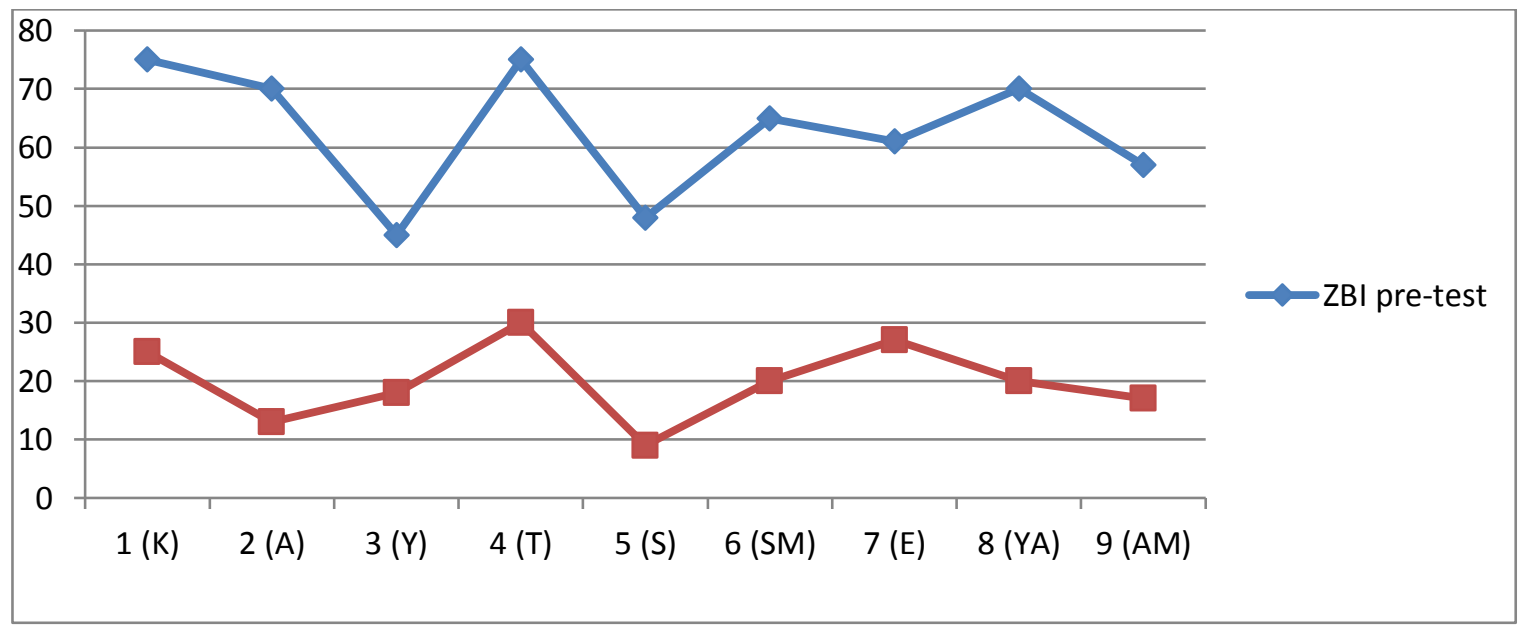

Gambar 1. Hasil Pengukuran Caregiver Burden Pra-Pascasesi Kelompok Dukungan 
Tabel 3.

Rangkuman Hasil Kelompok Dukungan

\begin{tabular}{|c|c|}
\hline Keberhasilan Kelompok Dukungan & Keterangan \\
\hline $\begin{array}{l}\text { Group cohesiveness dan belongingness } \\
\text { (rasa memiliki dalam kelompok) }\end{array}$ & Dirasakan oleh semua partisipan pada semua sesi \\
\hline $\begin{array}{l}\text { Installation of hope (Membangun harapan, } \\
\text { rasa percaya diri dan pandangan positif } \\
\text { tentang masa depan) }\end{array}$ & Dirasakan oleh semua partisipan pada semua sesi \\
\hline $\begin{array}{l}\text { Universality (Perasaan satu nasib, } \\
\text { berkurangnya perasaan terisolasi) }\end{array}$ & Dirasakan oleh semua partisipan pada semua sesi \\
\hline $\begin{array}{l}\text { Altruisme (Menjadi lebih bermanfaat bagi } \\
\text { orang lain) }\end{array}$ & Dirasakan oleh semua partisipan pada semua sesi \\
\hline $\begin{array}{l}\text { Mengurangi emosi } \quad \text { negatif } \\
\text { membangun dan } \\
\text { menerima kondisi dan } \\
\text { sendiri) }\end{array}$ & Dirasakan oleh semua partisipan pada semua sesi \\
\hline $\begin{array}{l}\text { Meningkatkan pemahaman tentang } \\
\text { gangguan skizofrenia }\end{array}$ & Dirasakan oleh semua partisipan pada semua sesi \\
\hline $\begin{array}{l}\text { Mempelajari keterampilan dalam proses } \\
\text { perawatan (cara berkomunikasi, mengatasi } \\
\text { stres dengan relaksasi, menghadapi anak } \\
\text { dengan skizofrenia dan kemampuan } \\
\text { coping skill lainnya) }\end{array}$ & $\begin{array}{l}\text { Dirasakan dan mulai diterapkan oleh partisipan dalam } \\
\text { proses perawatannya sehari-hari. Setiap partisipan } \\
\text { mempraktikkan keterampilan yang telah diajarkan } \\
\text { secara berbeda-beda. Contohnya, A mempraktikkan } \\
\text { relaksasi sedangkan AM tidak. AM mempraktikkan cara } \\
\text { berkomunikasi yang tepat kepada anak, sedangkan A } \\
\text { belum mempraktikkannya karena masih menunggu } \\
\text { waktu yang tepat. Secara umum mereka sudah memiliki } \\
\text { bekal pengetahuan dan mulai mempraktikkan } \\
\text { keterampilan tersebut. }\end{array}$ \\
\hline
\end{tabular}

Dari pengukuran tersebut, terlihat bahwa perbedaan skor ZBI antara sebelum dan sesudah menjalani intervensi berbeda secara signifikan dengan angka signifikansi di bawah 0,05. Hal ini menunjukkan bahwa intervensi yang dilakukan memberikan dampak yang tepat dalam aspek pengurangan skor beban yang dirasakan oleh partisipan penelitian. Paket intervensi yang disusun terbukti memiliki dampak terhadap penurunan skor beban ZBI para partisipan secara signifikan.

\section{Berlangsungnya kegiatan kelompok} dukungan ini tidak terlepas dari motivating force (dorongan motivasional) yang kuat pada partisipan sebagai alasan mereka untuk mengikuti kelompok dukungan. Dorongan motivasional ini disebabkan oleh tingginya beban, keterbatasan ruang gerak, rendahnya pengetahuan dan keterampilan, serta tingginya level dependensi dari care receiver (Toseland dkk., 2011). Hal ini disampaikan oleh semua partisipan sebagai alasan yang melatarbelakangi mereka mengikuti kelompok dukungan. Faktor kebutuhan dan motivasi dari partisipan untuk mengakses kelompok dukungan inilah yang membuat kelompok dukungan dapat berjalan secara rutin sesuai dengan rencana. Situasi ini sejalan dengan temuan Markowitz (2015) dalam penelitiannya yang menemukan tingginya keterlibatan partisipan ditunjang oleh rasa mendapatkan benefit dari kegiatan mengikuti kelompok dukungan. Selanjutnya, melalui intervensi kelompok dukungan ini terdapat beberapa faktor yang mendukung terjadinya perubahan beban yang dirasakan oleh semua partisipan. Nuansa mengenai benefit ini juga ditemukan pada riset mengenai pelaksanaan kelompok dukungan oleh Orne-Gliemann dkk. (2017) pada Ibu dengan HIV di Zimbabwe, yang menemukan banyak partisipan kelompok dukungan yang tidak meneruskan sesi karena memaknai diri mereka tidak mendapatkan keuntungan. 
Pertama, kelompok dukungan memunculkan perasaan tidak sendiri dan memberikan rasa aman bagi partisipan. Kehadiran orang lain dengan masalah yang sama (universality) menjadi anugerah dan bantuan bagi orang yang terlibat dalam support group (Corey, Corey, \& Corey, 2001). Melalui kelompok dukungan ini, partisipan tidak lagi merasa terisolasi dalam lingkungan sosialnya. Padahal, sebelumnya mereka harus berhadapan dengan emosi malu karena adanya stigma negatif dari lingkungan yang memanggil anaknya "gila". Oleh karena itu, saat mereka dikumpulkan dalam suatu kelompok dan bertemu dengan orang-orang yang senasib, kelompok dukungan dapat menjadi wadah untuk melakukan perubahan positif lainnya. Kesamaan ini juga membangun rasa saling memiliki dan membuat kohesivitas dalam kelompok cepat terbentuk (Chou dkk., 2002). Hal ini terungkap dalam wawancara pasca intervensi, di mana kesembilan partisipan mengungkapkan adanya perasaan lega dan terlepas dari beban karena mengetahui bahwa dirinya bukanlah satu-satunya orang yang merasa amat terbeban dengan tugas sebagai caregiver anak dengan skizofrenia.

Kedua, kelompok dukungan menyediakan tempat untuk mengekspresikan semua perasaaan, seperti perasaan pasrah, putus asa, rasa sakit, ketakutan, dan segala perasaan lainnya (Chou dkk., 2002). Sejak sesi awal, partisipan mendapatkan kesempatan untuk melakukan katarsis emosi tanpa adanya keinginan untuk membela posisi mereka. Padahal sebelum mengikuti kelompok dukungan, mereka seringkali merasa sungkan untuk berkeluh kesah kepada orang lain atas beban yang dirasakan. Hal ini memunculkan perasaan lega karena mereka merasa diterima oleh lingkungan. Ini sejalan dengan sifat dari kelompok dukungan yang dijelaskan dalam Kurtz (1997). Situasi ini tampak sangat dimanfaatkan oleh kesembilan partisipan, terutama $\mathrm{K}$ dan A yang awalnya merasa sungkan untuk menampilkan emosi yang ingin diungkapkan, sehingga beban emosi yang telah diekspresikan menjadi sangat turun bila dibandingkan dengan sebelum menjalani intervensi.

Ketiga, secara umum keluarga dengan skizofrenia memiliki sedikit informasi tentang skizofrenia, tetapi memiliki tanggung jawab yang besar untuk merawat (Bruhn \& Rebach, 2014). Hal tersebut juga terjadi pada semua partisipan dalam penelitian ini. Kondisi ini semakin buruk karena mayoritas partisipan yang terlibat dalam penelitian ini memiliki pendidikan menengah ke bawah. Mereka sulit mengakses dan memahami informasi yang diterima dari lembaga kesehatan profesional. Padahal, caregiver memiliki sense of idealism untuk melakukan segala sesuatu dengan sangat baik untuk care receiver (Carter dalam Bruhn \& Rebach, 2014). Harapan yang tidak tercapai karena pengetahuan dan keterampilan yang tidak memadai inilah yang menyumbang rasa kecewa, stres, dan frustasi yang terus menumpuk hingga menjadi beban. Salah satu contohnya adalah partisipan $\mathrm{Y}$, yang mengungkapkan dalam wawancara bahwa ia belajar banyak dari partisipan lain mengenai kiat-kiat menangani anak yang belum pernah ia lakukan sebelumnya. Adanya keberhasilan partisipan AM yang meski sudah jauh lebih senior, dengan segala kiat yang dilakukannya, membuat $\mathrm{Y}$ sangat terinspirasi dan juga termotivasi untuk merawat anaknya dengan berbagai cara alternatif sehingga tidak merasakan kebuntuan karena hanya menerapkan cara serta sudut pandang yang sama saja.

Melalui kelompok dukungan, partisipan dapat belajar bersama untuk meningkatkan pemahaman tentang suatu penyakit atau gangguan yang diderita seseorang (Toseland dkk., 2011). Kelompok dukungan memberikan kesempatan belajar dari pengalaman atau keterampilan orang lain dalam mengatasi masalah (Kurtz, 1997). Ketika pengetahuan semakin meningkat, rasa percaya diri dan harapan partisipan semakin terbangun karena mereka lebih siap dengan bekal pengetahuan yang ada. Hal ini ikut membangun perasaan lebih mampu 
menghadapi sesuatu yang sebelumnya tidak mampu dihadapi. Lebih jauh, hal yang menarik dari pelaksanaan kelompok dukungan ini adalah semua partisipan berupaya menerapkan pengetahuan yang didapatkan selama kelompok dukungan sesuai kebutuhan dan kondisi yang mereka hadapi. Hal ini diungkapkan para partisipan dalam wawancara, di mana sesi mengenai pemaparan informasi mengenai fenomena skizofrenia disampaikan, mereka menjadi lebih paham mengenai skizofrenia itu sendiri. Belum lagi, teknik-teknik menguasai diri, serta cara komunikasi yang dipelajari dengan lebih baik membuat mereka merasa punya harapan baru dalam menjalani harihari ke depan sebagai caregiver.

Keempat, dalam kelompok dukungan partisipan dapat saling mendukung dan memvalidasi emosi yang dirasakan satu sama lain (Corey dkk., 2001). Hal ini membuat partisipan termotivasi melakukan berbagai perubahan positif karena adanya dukungan sosial dan emosional dari lingkungan. Dukungan ini juga termanifestasi dalam bentuk pujian, seperti yang dilakukan oleh para partisipan kepada partisipan lainnya. Dengan demikian, mereka lebih mampu mengatasi perasaan negatif, membangun semangat, rasa percaya diri serta harapan terhadap masa depan. Kelompok dukungan yang memungkinkan adanya penyaluran emosi ini diakui para partisipan dalam wawancara menjadi titik kuat bagi mereka untuk tetap bertahan dan termotivasi. Selama ini mereka merasa sangat terbeban, utamanya bila tidak ada rekan yang sama-sama bertugas untuk menjadi caregiver di dalam keluarga. Mereka kemudian melihat adanya kekuatan karena perasaan yang mereka rasakan tervalidasi oleh masing-masing peserta lainnya. Perasaan yang sama dan tervalidasi, justru menurut mereka menguatkan tekad mereka untuk bertahan kuat sebagai caregiver bagi anak-anak mereka. Seluruh peserta mengungkapkan bahwa mereka memiliki emosi yang sangat negatif terkait situasi mereka sebagai caregiver. Baik itu terhadap anak mereka, juga terhadap keluarga serta diri mereka sendiri. Dalam proses intervensi, setiap perasaan ini tidak dibantah, namun diakui keberadaannya, dengan tujuan agar para partisipan menerima perasaan tersebut dan tidak menyangkalnya yang justru bisa membuat mereka menjalani proses emosi negatif yang lebih lama. Nuansa kuatnya validasi perasaan yang membentuk ikatan ini sejalan dengan temuan Chapman, Baker, Porter, Thayer, \& Burlingame (2010).

Kelima, keragaman partisipan yang terlibat dalam kelompok dukungan menjadi salah satu faktor keberhasilan kelompok dukungan ini. Partisipan yang terlibat memiliki durasi, lama merawat hingga pengalaman perawatan yang berbeda-beda. Bagi mereka yang memiliki pengalaman merawat lebih lama mendapatkan kesempatan untuk membantu partisipan lain yang memiliki kesulitan yang pernah mereka alami di masa lalu. Hal ini ikut mengembangkan pandangan dan perasaan lebih baik tentang diri sendiri, mengembangkan personal gratification (perasaan bermanfaat), sikap altrusime serta lebih mampu mengapresiasi diri sendiri (Whitaker, 2001). Perasaan positif tersebut akan mendorong perubahan cara pandang dalam melihat kondisi yang dinilai sebagai beban. Hal ini berlaku sebaliknya, bagi partisipan yang baru merawat memiliki kesempatan untuk belajar dari pengalaman partisipan lain. Mereka menjadi lebih percaya diri dengan melihat kemampuan partisipan lain yang sudah bertahan lebih lama dibandingkan diri mereka. Partisipan dengan pengalaman merawat lebih sedikit juga menunjukkan apresiasi terhadap perjuangan partisipan lain yang lebih lama dalam merawat. Proses timbal balik yang terjadi dalam kelompok ini memengaruhi penghayatan beban yang dirasakan sebelumnya oleh partisipan. Hal ini senada dengan temuan Pagano, Post, dan Johnson (2011) mengenai efek memberikan bantuan pada si pemberi bantuan itu sendiri juga.

Keenam, perbedaan usia juga ikut memengaruhi perubahan beban yang 
dirasakan. Dalam penelitian ini, rentang usia partisipan berkisar dari usia 45 tahun hingga 69 tahun. Jika mengacu pada Papalia, Old, dan Feldman (2008) dapat disimpulkan bahwa ada tujuh orang dengan usia yang berada pada fase dewasa madya dan dua orang yang berada pada fase dewasa akhir. Menurut Erikson (dalam Papalia dkk., 2008) partisipan yang berada pada masa dewasa madya memiliki tahap perkembangan generatifitas, di mana mereka mengembangkan perhatian yang berkaitan dengan membimbing dan memengaruhi orang lain. Dalam penelitian ini, partisipan yang berada pada masa dewasa madya mendapatkan kesempatan untuk menjadi 'helper' atau pemberi bantuan kepada partisipan lain dengan mengacu pada pengalaman hidup mereka selama merawat anak. Kemudian, pada usia ini umumnya mereka akan melakukan introspeksi yang mengarah kepada penilaian kembali (Papalia dkk., 2008). AM sebagai yang senior ternyata dilihat menjadi acuan untuk terus dapat berbuat yang terbaik bagi anak-anak partisipan. Pengakuan Y dan juga YA secara eksplisit mengenai kekaguman mereka akan kuatnya tekad AM meski usianya sudah cukup tua, membuat mereka tidak lagi ingin berfokus pada diri mereka sendiri. Mereka mengatakan bahwa mereka mau lebih mengedepankan emosi positif dalam menjalani tugas mereka sebagai caregiver. Melalui sesi sharing dalam kelompok dukungan, secara tidak langsung partisipan kembali mengulas masa lalunya. Kemudian, mereka melakukan introspeksi yang mengarah pada tilikan-tilikan positif yang mereka temukan.

Kemudian, bagi partisipan yang berada pada masa dewasa akhir, mereka melalui tahap perkembangan integritas ego versus keputusasaan (Papalia dkk., 2008). Dapat dikatakan, saat ini mereka mengalami keputusasaan dan reduksi gradual terhadap keterlibatan sosial. Melalui kelompok dukungan ini, khususnya partisipan yang berada pada tahap dewasa akhir memiliki kesempatan untuk terlibat pada aktivitas sosial dan memiliki kesempatan untuk berbagi dan merefleksikan pengalamannya. Kelompok dukungan juga memberikan kesempatan untuk mengapresiasi diri mereka sebagai orangtua yang telah melakukan hal terbaik yang dapat mereka lakukan (Papalia dkk., 2008).

Ketujuh, keberhasilan pelaksanaan kelompok dukungan tidak terlepas juga dari kehadiran peneliti yang bertindak sebagai profesional. Menurut Kurtz (1997) faktor kuratif dalam kelompok muncul dalam bentuk membantu problem solving dan mempelajari teknik relaksasi. Hal ini diberikan oleh peneliti sebagai fasilitator profesional dalam rangka membantu mengurangi beban yang dirasakan oleh caregiver. Selain itu, hal yang terpenting adalah caregiver merasa senang dengan kelompok dukungan karena adanya seorang professional yang akhirnya mendengarkan dan memahami sisi lain dari mereka (Yalom dalam Kurtz, 1997). Proses ini kemudian memengaruhi penilaian positif atas diri mereka dan proses perawatan yang telah dilakukan.

Secara keseluruhan, kelompok dukungan ini telah berhasil mengatasi beban pada caregiver. Proses dalam kelompok dukungan mampu mengatasi masalah emosional dan praktis dari perawatan. Menurut Cooke dkk. (dalam Toseland dkk., 2011) dukungan sosial dalam intervensi atau kombinasi dukungan sosial dan kognitif dalam pemecahan masalah memang lebih efektif. Hal inilah yang membuat kelompok dukungan berhasil dalam mengatasi beban caregiver skizofrenia. Selain itu, hal yang juga penting adalah para partisipan memiliki semangat untuk terus membangun afiliasi dalam kelompok. Mereka memiliki sense of belonging yang kuat serta berupaya membuat kegiatan kelompok dukungan berlangsung secara terus menerus.

Dalam penelitian ini masih ada beberapa hal yang dapat disempurnakan dalam penelitianpenelitian selanjutnya. Pada aspek partisipan, pemetaan tingkat pendidikan perlu menjadi 
perhatian khusus agar materi yang disampaikan dapat disesuaikan dengan tingkat pemahaman partisipan. Bahasa yang tergolong akademik dan teoritik menjadi faktor penyulit partisipan untuk memahami materi. Pengisian alat ukur ZBI yang berbahasa alat ukur baku juga menjadi faktor penyulit bagi partisipan. Mengacu pada latar belakang partisipan yang tidak mengenyam sekolah tinggi, bahkan sekolah menengah, maka kesulitan ini dapat dimaklumi. Penyesuaian bahasa pengantar dalam materi harus dilakukan apabila kelompok dukungan ini akan dilaksanakan pada partisipan dengan karakteristik pendidikan serupa. Adanya asisten peneliti yang cukup untuk membantu pengisian alat ukur juga penting untuk dipertimbangkan agar pengisian alat ukur tepat sesuai dengan tujuan.

Hal berikutnya yang perlu diperhatikan adalah perlunya indikator data kualitatif yang lebih jelas dan terstrukur agar analisis wawancara dapat lebih akurat. Dengan lebih tajamnya struktur wawancara, akan memperkuat penyempurnaan intervensi karena dapat lebih tajam mengintervensi aspek spesifik. Setelah itu, pelaksanaan follow-up terhadap perkembangan dari partisipan dan kelompok merupakan suatu kegiatan yang penting. Follow-up dapat dilakukan dalam jangka waktu tiga bulan, enam bulan hingga satu tahun. Fasilitator juga sebaiknya dapat melibatkan dan mempersiapkan kader wilayah agar terus terlibat aktif dalam pelaksanaan kelompok dukungan. Pelatihan ini berkaitan dengan topik mengenai pelaksanaan kelompok dukungan, mengatasi beban psikologis sebagai caregiver dan peran spesifik yang dapat kader lakukan dalam intervensi kelompok. Pemberian materi mengenai relaksasi pernafasan seharusnya diberikan beberapa kali, tidak hanya satu kali saja. Hal ini dikarenakan relaksasi adalah sebuah teknik yang sebaiknya terus dilatih dan dibiasakan agar partisipan dapat melakukannya dengan lebih baik. Pada sesi selanjutnya, teknik relaksasi juga dapat dijadikan sebagai pembuka atau penutup sesi dalam kelompok dukungan yang dapat membuat suasana hati partisipan menjadi lebih relaks.

\section{SIMPULAN}

Hasil penelitian ini menunjukkan bahwa intervensi kelompok dukungan berhasil menurunkan tingkat beban pada caregiver yang merawat anak dengan skizofrenia di Rumah Sakit X. Secara kualitatif, seluruh partisipan merasakan manfaat intervensi kelompok dukungan untuk mengatasi beban mereka sebagai caregiver. Secara kuantitatif, semua partisipan juga terlihat mengalami penurunan skor beban yang dirasakan selama merawat anak dengan skizofrenia. Kelompok dukungan membantu partisipan untuk memiliki pikiran yang lebih positif, mengendalikan emosi negatif, dan menemukan makna positif, serta harapan baru tentang masa depan. Dari dinamika kelompok yang terjadi, mereka juga mengakui mendapatkan pengetahuan serta keterampilan baru mengenai strategi mengatasi beban sebagai caregiver dan cara merawat anak dengan skizofrenia. Selain itu, partisipan juga merasakan kebersamaan dalam kelompok yang terwujud dalam kohesivitas kelompok dan sense of belonging yang kuat.

\section{DAFTAR PUSTAKA}

Adelman, R. D., Tmanova, L. L., Delgado, D., Dion, S., Lachs, M. S. (2014). Caregiver Burden, A Clinical Review. JAMA Clinical Review \& Education, 311(10), 1052-1059.

Angermeyer, M. C., Schulze, B., Dietrich, S. (2003). Courtesy stigma, a focus group study of relatives of schizophrenia patients. Soc. Psychiatry Psychiatr Epidemiol, 38, 593-602. DOI: 10.1007/s00127-003060-x.

Armandani, K. (13 Oktober 2014). Nasib pengidap skizofrenia di Indonesia. CNN Indonesia. Diunduh dari 
http://www.cnnindonesia.com, pada tanggal 1 Februari 2016.

Bharti, J. (2015). Burden among caregivers of person with schizophrenia and schizoaffective disorder: A comparative study. The International Journal of Indian Psychology, 2(4), $136-147$.

Bruhn, J. G., \& Rebach, H. M. (2014). The sociology of caregiving: Clinical sociology, Research and practice. New York: Springer Science.

Chapman C.L., Baker E. L., Porter, G., Thayer S. D., Burlingame, G. M. (2010) Rating group therapist interventions: The validation of the Group Psychotherapy Intervention Rating Scale. Group Dynamics: Theory, Research, and Practice, 14(1), 15-31.

Chien, W. T. (2008). Effectiveness of psychoeducation and mutual support group program for family caregivers of Chinese people with schizophrenia. Open Nursing Journal, 2, 28-39.

Chien, W. T., Chan, S. W. C., \& Thomspon, D. R. (2006). Effects of a mutual support group for families of Chinese people with schizophrenia: 18 month follow up. British Journal of Psychiatry, 189, 41 - 49.

Chime, O. H., Arinze-Onyia, S. U., Obionu, C. N. (2018). Do peer support groups have an effect on medication adherence? A study among people living with HIV/AIDS in Enugu State, Nigeria. Proceedings of Singapore healthcare 2018, 27(4), 256-264.

Chou, K.R., Liu, S. Y., \& Chu, H. (2002). The effects of support groups on caregivers of patient with schizophrenia. International Journal of Nursing Studies, 39, 713 - 722.

Corey, M. S., Corey, G., \& Corey, C. (2001). Groups: Process and practice. California: Brooks/Cole.

Duxbury, L., Higgins, C., \& Schroeder, B. (2009). Balancing paid work and caregiving responsibilities: A closer look at family caregivers in Canada. Canada: Human Resources and Skills

Gravetter, F. J., \& Forzano, L. B. (2016). Research methods for the behavioral sciences. United States if America: Cengage Learning.

Guan, L., Xiang, Y., Ma, X., Weng, Y, \& Liang, W. (2016). Qualities of life of patients with psychotic disorders and their family caregivers: Comparison between hospitalised and community based treatment in Beijing, China. Plos ONE, 11(11), 1-12. DOI: 10.1371/journal.pone.0166811.

Gupta, A., \& Sharma, R. (2013). Burden and coping of caregivers of physical and mental illnesses. Delhi Psychiatry Journal, 16(2), 367-374.

Gupta, A., Solanki, RK., Koolwal, GD., \& Gehlot, S. (2014). Psychological well-being and burden in caregivers of patients. International Journal of Medical Science and Public Health, $4,70-76$.

Hebert, R., Bravo, G., \& Preville, M. (2000). Reliability, validity, and reference values of the Zarit Burden Interview for assessing informal caregivers of community dwelling older persons with dementia. Canadian Journal on Aging, 19, 494-507.

Henriksson, A., Arestedt, K., Benzein, E., Ternested, B., Andershed, B. (2012). Effects of a support group 
programme for patients with lifethreatening illness during ongoing palliative care. Palliative Medicine 27(3), 257-264.

Jungbauer, J., Wittmund, B., Dietrich, S., \& Angermeyer, M. C. (2004). The disregarded caregivers: Subjective burden in spouses of schizophrenia patients. Schizophrenia Bulletin, $30(3), 665-675$.

Kerlinger, F. N., \& Lee, H. B. (2000). Foundations of behavioral research $\left(4^{\text {th }}\right.$ Ed.). Forth Worth: Harcourt College Publishers.

Kim, H., Chang, M., Rose, K., \& Kim, S. (2011). Predictors of caregiver burden in caregivers of individual with dementia. Journal of Advanced Nursing, $846-855$.

Kring, A. M., Johnson, S. L., Davidson, G, C., \& Neale, J. M. (2012). Abnormal Psychology (12 ${ }^{\text {th }}$ Ed.). New Jersey: John Wiley \& Sons.

Kumar, K., \& Gupta, M. (2014). Clinical and socio-demographic determinants of psychological health and burden in family caregivers of patient with unipolar depression. Asian Journal of Psychiatry, 9, 51 - 56.

Kurtz, L. F. (1997). Self help and support groups. A handbook for practitioners. California: SAGE Publications, Inc.

Larson, J. E., Corrigan, P. (2008). The stigma of families with mental ilness. Academic Psychiatry, 32(2), 87-91.

Magnani, D., Lenoci, G., Balduzzi, S., Artioli, G., \& Ferri, P. (2017) Effectiveness of support groups to improve the quality of life of people with idiopathic pulmonary fibrosis a pre-post test pilot study. Acta Biomed for Health Professions. 88, 5-12.
Markowitz, F. E. (2015). Involvement in mental health self-help groups and recovery. Health Sociology Review, 24(2), 199-212.

Navidian, A., Kermansaravi, F., \& Rigi, S. N. (2012). The effectiveness of group psycho-educational program on family caregiver burden of patients with mental disorder. BMC Research Notes, 5, 399.

Ohaeri, J. U. (2001). Caregiver burden and psychotic patients' perception of social support in a Nigerian setting. Soc. Psychiatry Psychiatr Epidemiol, 36, 86-93.

Orne-Gliemann, J., Font, H., Maphosa, T., Kangwende, A., Rusakaniko, S., Magezi, V., Sengai, T., Shumba, B., Zambezi, P., Foster, G. (2017). Patterns of attendance at mother support groups in Zimbabwe. The EPAZ trial (2014-2016). Acquired Immune Deficiency Syndromes, 75, Supplement 2, S216-S223.

Pagano, M.E., Post, S.G., \& Johnson, S. M. (2011). Alcoholics Anonymousrelated helping and the helper therapy principle. Alcoholism Treatment Quarterly, 29(1), 23-34.

Panayiotopoulos, C., Pavlakis, A., \& Apostolou, M. (2013). Family burden of schizophrenic patients and the welfare system; the case of Cyprus. International Journal of Mental Health Systems, 7(13), 2-9.

Papalia, D. E., Old, S. W., \& Feldman, R. D. (2008). Human development $\left(9^{\text {th }} \mathrm{Ed}\right)$. New York: The McGraw Hill Companies.

Poerwandari, E. K. (2013). Pendekatan kualitatif untuk penelitian perilaku manusia. Depok: Lembaga 
Pengembangan Sarana Pengukuran dan Pendidikan Psikologi Universitas Indonesia.

Pratima, B., \& Jena. (2011). Caregiver burden in severe mental illness. Delhi Psychiatry Journal, 14(2), 211-219.

Seng, B. K., Luo, N., Ng, W. Y., Lim, J., Chionh, H. L., Goh, J., Yap, P. (2010). Validity and reliability of the Zarit Burden Interview in assessing caregiving burden. Annals of The Academy of Medicine, 39, 758-763.

Schene, A. H., Wijingaarden, B., \& Koeter, M. W. J. (1998). Family caregiving in schizophrenia: Domains and
Distress. Schizophrenia Bulletin, 24(4), 609-618.

Toseland, R. W., Haigler, D. H., \& Monahan, D. J. (2011). Education and support programs for caregivers: Research, practice, policy. New York: Springer.

Whitaker, D. S. (2001). Using groups to help people. Oxford: Brunner-Rotledge.

Wiener, Z. (2011). A risk and resistance model for predicting maternal psychological distress to autism: Caregiver burden, uncertainty, and optimism (Dissertation). http://fordham.bepress.com/dissertati ons/AAI3475199. New York: Fordham University. 